\title{
Intelligent Organization Management by Means of Categorizing Resources, Processes and Goals
}

\author{
Gennady Kulikov \\ Ufa State Aviation Technical University \\ Ufa, Russia \\ gennadyg_98@yahoo.com
}

\author{
Vyacheslav Antonov \\ Ufa State Aviation Technical University \\ Ufa, Russia \\ antonov.v@bashkortostan.ru
}

\author{
Konstantin Konev \\ Ufa State Aviation Technical \\ University \\ Ufa, Russia \\ sireo@ rambler.ru
}

\begin{abstract}
The article is devoted to the issues of increasing the efficiency of organization management. To solve the problem, it is proposed to build a mechanism of gradual creation intelligent of the organization management system. As a tool for the formation of this mechanism, it is proposed to create an integrated ontological model of the organization, providing a categorization of the organization's business processes and related resources, rules (restrictions) and goals. To ensure the continued suitability of such a model, it is intended to be endowed with the property of self-actualization. As an example, we consider the business process of researching a product returned from operation at an aviation instrument making enterprise.
\end{abstract}

Keywords-organizational management, intelligent management, ontological organization model, selfactualization, categorization.

\section{INTRODUCTION}

Recently, more and more facts indicate that the sphere of management and the mechanisms that form specialists in this field are not sufficiently balanced, as indicated by many researchers $[1,2]$. Simply put, the system of training managers is not fully cope with the task of training adequate staff. For this reason, not only start-ups, but also large, once quite successful enterprises, are falling into decay. As vivid examples of this phenomenon, we can recall the fate of the companies Mexx Group B.V., Lehman Brothers, Colt Defense and the bankruptcy of the city of Detroit [3]. Each of these giants collapsed due to its unique causes and quite specific problems, but inadequate adequate management was a common place in almost all situations, the mistakes and incompetence of which were reinforced by negative external factors. Of course, the problem of reducing the quality of managerial decisions has many aspects, including cultural, historical, psychological, political, etc. $[4,5]$.

A lot of scientists from different countries of the world are involved in researches of various aspects of these phenomena, but in the article we will limit ourselves to the technical aspect of this problem and offer technical approaches to its solution. We will consider the approach to creating an effective tool for organization managers, which will help increase they productivity and reduce the number of errors.

\section{THE TECHNICAL SIDE OF THE PROBLEM OF} INSUFFICIENT EFFICIENCY OF MODERN MANAGEMENT

Consider the work of the head of a large organization. In general, this is a constant communication with the leaders of other organizations and direct subordinates, who are also heads of major activities. The manager cannot directly participate in the organization's business processes and has to rely on the opinions and evaluations of other persons, who also, as a rule, base their judgments on the basis of the opinions and evaluations of the heads of specific departments or experts. And the more levels of management, the more subjects influence the information on the basis of which the most important decisions are made in the organization. Modern approaches to organizational management offer many ways to solve this problem $[6,7,8]$, but large organizations that have existed for decades continue to go bust, and not always when their life cycle is fully passed. The reason, in our opinion, is in human nature, since human consciousness, in principle, cannot hold as many objects as it needs to be processed for effective management of a large organization. As a result, the manager has to concentrate on only a few important topics, and the rest, in essence, is left to others persons. With proper selection of these persons, this scheme gives satisfactory results, but as the complexity of business processes grows, these persons - the assistants to the head of the organization, are extremely overloaded with information and have to take beyond the scope of their attention the activities of entire departments. At some point, the external environment may change in such a way that the previously minor process or function begins to play the most important role, and the manager may not notice this change or be unable to correctly orient and form the necessary managerial actions. As a result, the company suffers losses, and competitors squeeze it out of the market.

Thus, we can conclude that the main obstacle to improving the efficiency of modern management is the very nature of man, his psychological and intelligent capabilities, which with the increasing complexity of the structure of the organization becomes insufficient. However, this does not mean that humanity has reached the peak of development and there is nowhere else to develop. A person in many areas of his life has long gone beyond the capabilities of his body or mind. 
It is also advisable to do in organizational management.

The modern computing system beats even outstanding chess players in chess. The reason for this is that, unlike a person, system is able to handle much more options for the development of the situation and for a much larger number of steps forward. Similarly, in the management at the final stage of the evolution of organizational management, the intelligent mechanism, not the person, will become the head of organization. No matter how scary such a prospect is, this is objective, since the head solves similar optimization problems as a chess player, but only in a much larger space of possible situations, rules and restrictions. However, a high-performance processor can collect, iterate and optimize all the solutions to each of the many problems of a large organization.

It is also clear that today such an "ideal manager" has not been created and, most likely, at the current stage of technology development is not possible in principle. The reasons for this include the lack of quality models for making optimal decisions in various areas of activity, the lack of mechanisms for updating such models, the lack of effective methods for assessing the consequences of such automation, etc. But the main problem is the lack of meta-rules for creating an "ideal manager", i.e. a general model of transition from the classical approach, which linked any management with the specification of consciousness the certain person, to a new approach, in which the artificial intelligent system will make management decisions. Without the development of such meta-rules, further movement in this direction will be a walk in the dark. Quite a lot of researches has been devoted to the study of improving the quality of management in social and technical systems (for example, [9, 10], etc.). Some researchers bring the question to the construction of a meta-model or organization ontology $[11,12,13]$. We will take a similar approach in this text and try to outline some of the outlines of the organization's meta-rules.

\section{THE CONCEPT OF AN “IDEAL MANAGER” AS A NEW PHILOSOPHY OF ORGANIZATIONAL MANAGEMENT DEVELOPMENT}

It is known that each organization can be represented as a set of goals (tasks), resources, rules (limits) and processes (functions, operations, technologies). These components are characterized by the following levels: unformalized, formalized, automated, or intellegent.

Accordingly, the movement from non-formalized goals, resources, rules and processes to the intelligent ones will be the vector of the evolution of organizations. By the way, today this vector is designated even at the level of public policy under the name of digitalization, but, unfortunately, the task is limited only to the creation of new management services.
If we tie this development vector to existing information technologies, then we can propose the some stages structure.

At the lower (initial) level there will be a class of corporate information systems, within which the individual components are not integrated with each other and with the organization's management system.

At the next level (integration) in the organization, measures will taken to link the set of used information systems into a single system, the automation concept will be formed and a relatively complete model of the organization's processes and projects would be built.

At the third level (managed) in an organization, all components of information systems will not only be linked together, but will also receive an automated information interface with the management of the organization, i.e. the manager will be able to receive information of the work of the processes and projects directly from the information interface of the corresponding subsystem of the information system, as well as realize directly communicate with management objects (personnel and information subsystems) to issue instructions within their authority (for example, initiate a conveyor stop or postpone of a project). In addition, the organization will be able to build a management model that allows its to have a ready-made algorithm of actions in typical management situations and this model will be implemented in the information system.

At the fourth level (quality of management), a mechanism will be implemented for automatic assessment of the quality (adequacy and effectiveness) of management decisions made, as well as the risks associated with them. In addition, the information system will have an embedded knowledge base on typical management situations and a mechanism for generating the most preferred solution in a particular situation in the mode of information support for a manager. The knowledge base should be linked to the mechanism for assessing the quality of previous decisions.

At the fifth level (ideal), mechanisms of intelligent decision-making and assessment of their consequences should be created, which would allow to completely exclude a person from the management system of the organization while ensuring the adequacy and effectiveness of the implemented management.

Movement from the initial level to the highest will be a very good tactic for the development of the organization's management system.

\section{BUILDING MECHANISMS TO ENSURE THE EVOLUTION OF THE ORGANIZATIONAL MANAGEMENT SYSTEM}

A technically "ideal manager" is an information system with an intelligent component, which is based on both the components of a classic corporate information system (CIS) and:

- a model of the organization acting as a management object, presented in the form of a 
comprehensive formalized description of all the processes and projects of the organization that are significant for management;

- management model in the form of a set of algorithms for making standard management decisions for each process, project and organization as a whole;

- an intelligent add-on that can adapt the organization model and management model to maintain the ability to generate adequate and effective solutions;

- an intelligent add-on capable of generating adequate and effective solutions in atypical, new situations;
- mechanism for the automatic implementation of decisions;

- a mechanism for assessing the quality (adequacy and effectiveness) of typical management decisions technologies that will undoubtedly arise in the future. However, it reflects the overall concept of the system.

- an intelligent mechanism for assessing the quality of new managerial decisions.

Schematically, the mechanism for implementing the "ideal manager" system is shown in Fig. 1.

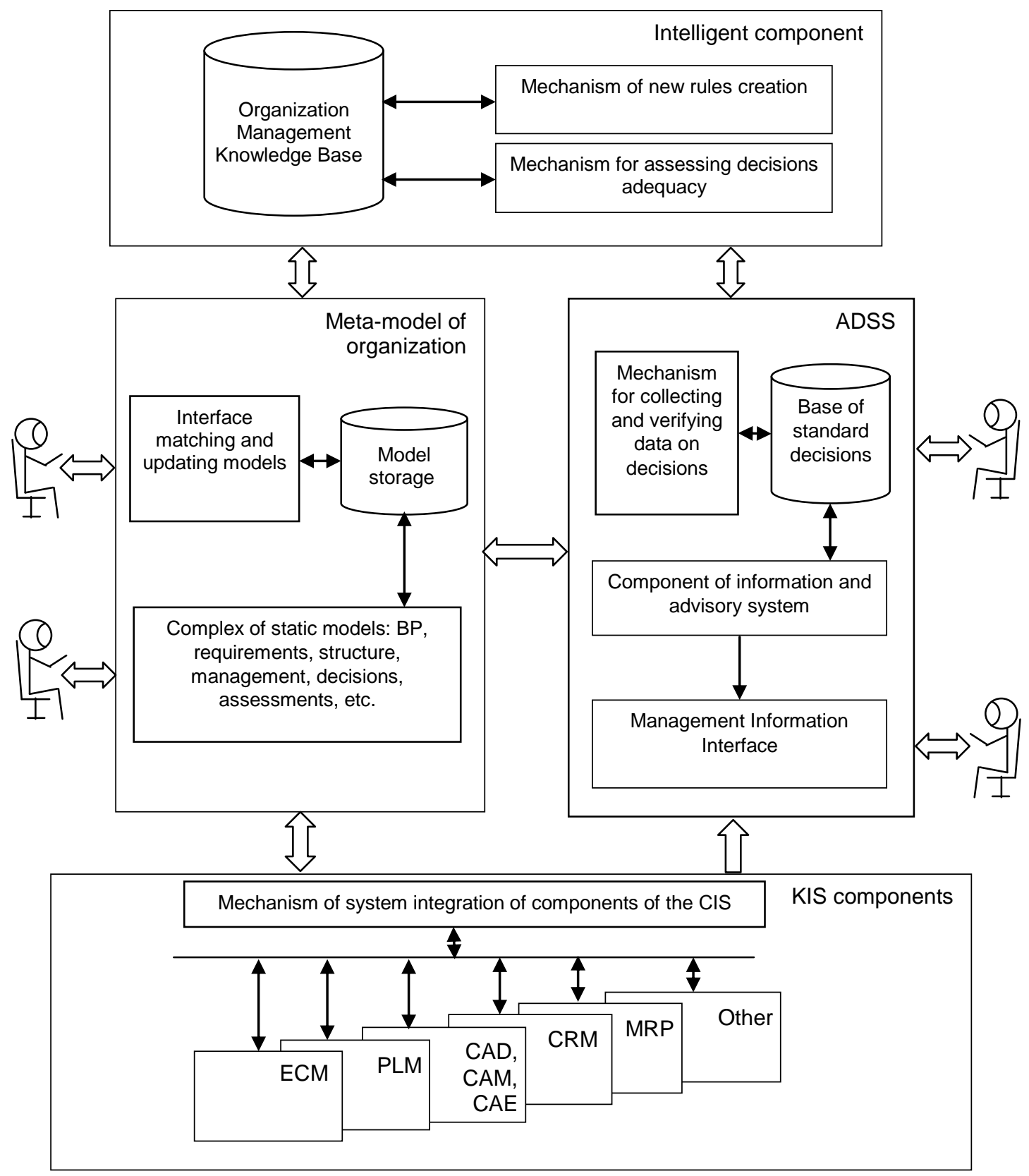

Fig. 1. Scheme of ideal organization management 


\section{CONSTRUCTION OF META-RULES OF THE} ORGANIZATION'S ONTOLOGY AS A PROTOTYPE OF THE INTELLIGENT COMPONENT OF THE “IDEAL MANAGER" SYSTEM

The most important component of the organizational management system of the future, of course, should be its intelligent component. It is in its depths that the solutions to any problems of the organization should be generated and the most optimal of them should be selected. Today this topic is the most problematic due to the highest diversity of business processes of different organizations in different spheres of human activity. Nevertheless, it is possible and meaningful to formulate some approaches to the formation of this component.

The first element of the intelligent component is a dictionary of concepts that are used in the subject area. It would be more correct to say not a dictionary, but an ontology of concepts linked between themselves and the conceptual apparatus of business processes by relations of categorization and association. Let's form the rules for such categorization:

- $\quad B P$ - the set of all processes;

- $R$ - the set of all the resources of the organization;

- $\quad G$ - the set of all goals;

- $\quad L$ - many restrictions and rules.

Within a business process, resources are converted for certain purposes based on certain rules, i.e. the sets $R, G, L$ belong to the set $B P$.

A set of informational characteristics of a business process, relationships and rules for establishing relationships can be used to formally define it as a tuple of components, which will give an expression:

$$
B P=\{R, G, L\},
$$

In this case, goals, resources, processes and rules (restrictions) can be built into a hierarchy that will correspond to the hierarchy of the organization. In other words, the processes, goals, resources and rules (restrictions) of the top leader can be presented as more general categories for similar elements of the heads of the organization's activities, which, in turn, can also be represented as a composition of elements at lower levels.

If you imagine the organization management structure $(E n)$ as the top component of the hierarchy, then from the point of view of the system analysis hierarchy principle [14], business processes can be viewed as a component of the next level hierarchy. Further when looking within business processes you can see functions (works) that can be also decomposed as a composition of operations and so on.

$$
E n=\left\{B P, \gamma_{B P}\right\},
$$

Where $\gamma_{B P}$ - business process categorization relationship.
To create a dynamic model from an interconnection model of organization, it is necessary to introduce the concept of a situation and a variety of situations $S$ that arise in the process of transforming resources according to the rules of business processes with some goals (quantitative and qualitative) taking into account of specified rules and restrictions. Situations can also be deployed at each level of the organization hierarchy. For each situation, the characteristic structure of states, in some of which (states of management decisions), it is necessary to make a decision, i.e. realize selection of variants and the selection of the most optimal of them within the framework of existing limitations and goals.

If we consider business processes taken from specific organizations, then it becomes possible to build an ontology that links business processes, resources, goals, and rules (restrictions). For example, for an educational institution, the main educational business process will include resources (audiences, teachers' competences, methodological materials, educational technologies and equipment), goals (competence formation, successful participation of students in specialty competitions, successful employment of graduates, etc.) rules (federal educational standards, internal regulations of the university, the law on education, etc.). If you build reference books for each type of the listed elements, then it becomes possible to form an ontological model of the educational process. Similarly, this approach is applicable to other business processes for a variety of subject areas.

Consider as an example aviation instrument enterprise. Suppose you need to build an ontological model of the business process of researching a product returned from service. Due to the impossibility of disclosing specific technological characteristics and the limited size of the article, we limit ourselves to listing the most meaningful functions of this business process:

- acceptance of the returned product from operation with registration of the act;

- research of the returned product to confirm the claimed defect with the registration of the act;

- in case of confirmation, to search for the causes of the defect and forming a decision on the future fate of the product;

- in case of not confirmation, to registrate of the relevant act and sending it with the product to the operating organization;

- research of the returned product in order to find the technical reasons for the claimed defect with the registration of the act;

- if a decision is made about the impossibility of recovering the product, sending a similar product for replacement; 
- if a decision is made to repair the product, to form a defect list and transfer it with the product to the own production;

- if the cause of the defect arose through the fault of the enterprise, to form of a plan for eliminating of the identified causes and prevent such defects in the enterprise;

- $\quad$ product repairing in production;

- $\quad$ acceptance tests of the restored product;

- if the test results do not match, to return for refining to the production;

- if the test results are consistent, to return the product to the operating organization.

In the form of a diagram of a business process is shown in Fig. 2.

Assume the process resources are: personnel $(P)$, research methods $(S)$, repair technologies $(T)$, repair materials $(M)$, products from the exchange fund $(R P)$, etc.

$$
R=\{P, S, T, M, R P\},
$$

The rules of the business process are set in GOST R 15.601, GOST R 15.307, the organization standard for organizing repairs $(N)$, etc., as well as the restrictions imposed by the practice of providing trade secrets, ethics, corporate requirements for personnel, the working hours of the organization $(B)$, etc.

$$
L=\{N, B\},
$$

The management objectives for the business process may include preventing defects $(D)$, minimizing reputation losses $(I)$, minimizing repair costs $(C)$, which can generally be displayed as follows:

$$
G=\left\{\begin{array}{c}
D \rightarrow 0, \\
I \rightarrow \min , \\
C \rightarrow \min .
\end{array}\right.
$$

The imposition of resources, rules (restrictions) and management objectives can be on the functions of the business process can be carried out as follows:

- Determination of process functions which ensure the achievement of specific management objectives;

- Determination the set of requirements (restrictions) that apply to them for the selected functions;

- Selection for each function a set of resources that are used for its implementation or are formed by it;

- Collation each element of the resulting model with a certain notion (category), which has a strict unambiguous interpretation.

The representation obtained in this way will have the form of an ontological model.

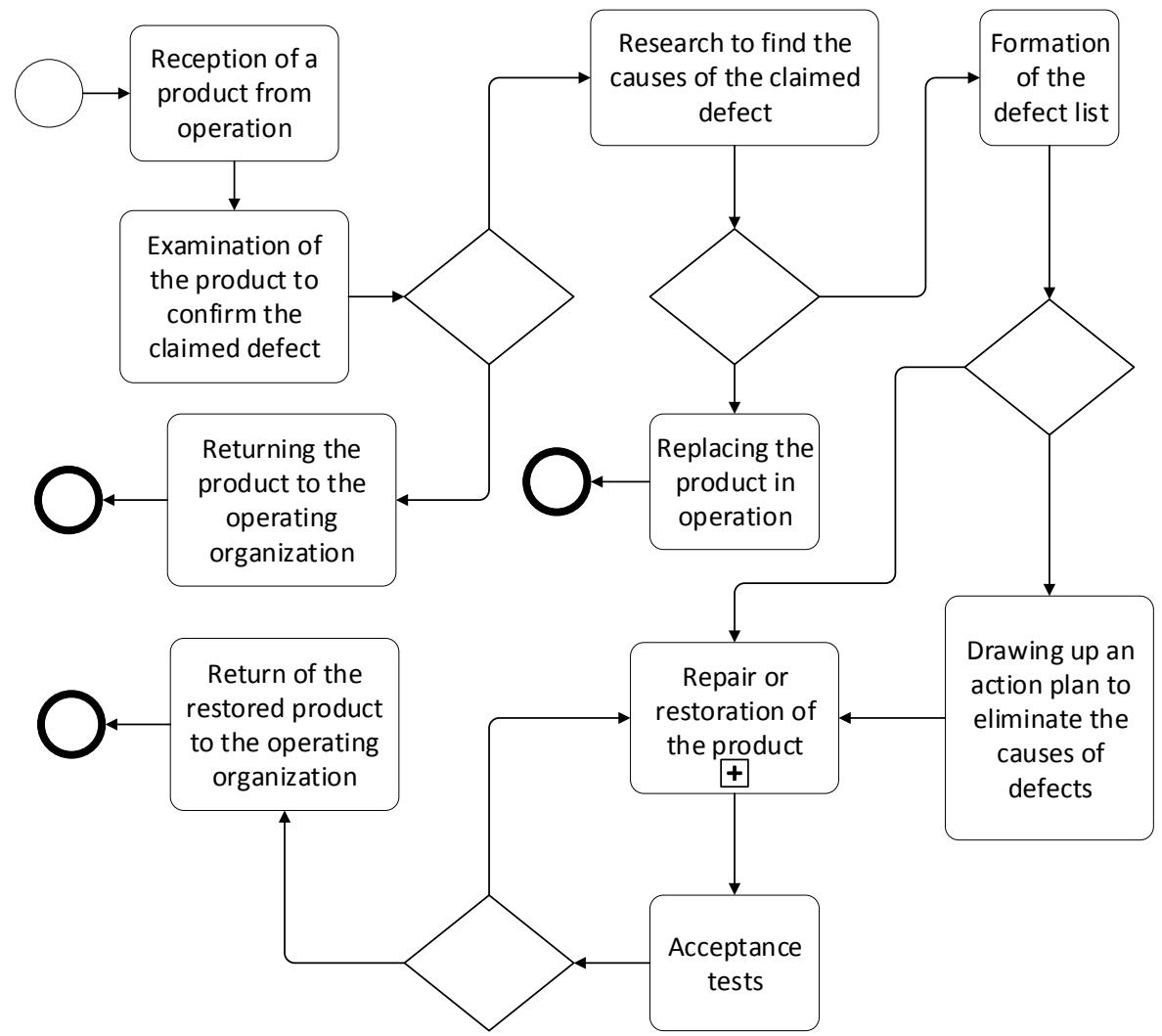

Fig. 2. Scheme of business process of researching a product returned from service 


\section{MECHANISM OF SELF-ACTUALIZATION OF THE INTELLIGENT COMPONENTS OF THE ORGANIZATION}

The most important, in our opinion, element of the organizational management system of the future is the mechanism for keeping all parts of the organization's intelligent component up to date. The way to put such a mechanism into practice is the development and inclusion of an ontology in the regulatory and technological documents of an organization so that the refinement of any instruction, regulation and even the form of a document is impossible without specifying the ontology in the notation in which it is stored in the enterprise. To do this, it is necessary to develop a special software product that allows you to create both an ontological model and generate different types of regulatory and technological documents from it - the universal document editor.

The next significant component is the mechanism for preserving the experience of managers. All situations requiring decision-making should be identified and included in the ontology. Any new management decisions should be recorded in the system to update its experience. Over time, the ontology should develop to such a level that it will be possible to automatically select solutions at every level of the hierarchy of the organizational system. The task of the manager will be narrowed down to choosing a solution from the proposed list or forming a new, not previously used solution. However, today the issue of fixing all decisions and, moreover, their subsequent evaluation is not solved due to psychological reasons and a lack of understanding of the possible benefits from this in the future.

The problem solution of preserving the managers experience and transfer of communication between levels of the hierarchy into the information environment is achieved by generating instructions on the meta-rules of the management language, which

can be analyzed automatically, highlighting problem statements, problem descriptions, instructions, etc. This approach will allow the computer to select the necessary entities and integrate them into the model.

Schematically, the self-actualization model is shown in Fig. 3. Conclusion

Despite the objective limitations of the physical abilities of a person, large and highly complex organizational systems are managed. The future is in intelligent systems that can partially or completely replace a person in the process of managing material production. In order to bring this future closer today, it is necessary to build ontological models of organizations that combine processes, resources, rules (restrictions) and goals. The key to successful implementation of such models is the use of modern information technologies and the approach to creation of ontologies self-actualization mechanism.

In the following articles, we intend to more closely examine the ontological model of one of the business processes of the specific organization, as well as approaches to creating software to support it.

\section{REFERENCES}

[1] T.V. Naumenko, "Paradigmal Foundations for Overcoming the Crisis of Economic Theory", IOP Conference Series: Materials Science and Engineering, Moscow, 2018, 463(4), 042092.

[2] A. Diez-Olivan, J. Del Ser, D.Galar, B.Sierra, "Data fusion and machine learning for industrial prognosis: Trends and perspectives towards Industry 4.0”. Information Fusion, 2019, № 50, p. 92-111.

[3] Billions in Debt, Detroit Tumbles Into Insolvency. The New York Times (2013-07-018).

[4] P. Puranam, The microstructure of organizations. Oxford Scholarship Online, 2018. 201 p.

[5] M. Zarte, A. Pechmann, I.L. Nunes, Decision support systems for sustainable manufacturing surrounding the product and production life cycle - A literature review. 2019. Journal of Cleaner Production 219, c. 336-349.

Document

generated from

model

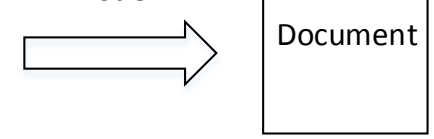

Process model

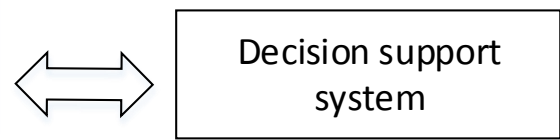

Process Information Specifying Model
Solutions

Decisions

taken

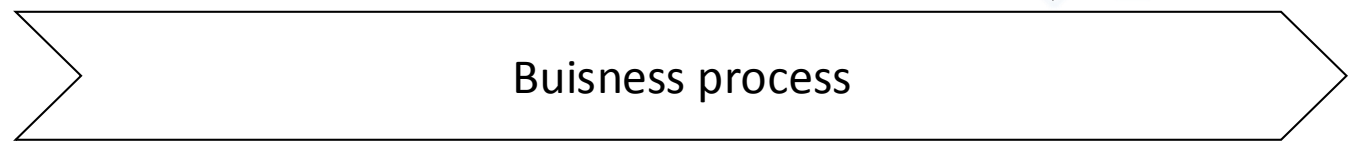

Fig. 3. Scheme of the mechanism of self-actualization of the ontological organization model 
[6] L. Massel, A. Massel, "Intelligent support tools for strategic decision-making on Smart Grid development", E3S Web Conf., Volume 69.

[7] B. Barann, "An is-perspective on omni-channel management: Development of a conceptual framework to determine the impacts of touchpoint digitalization on retail business processes". 26th European Conference on Information Systems: Beyond Digitization - Facets of Socio-Technical Change, ECIS 2018.

[8] M. Sasgratella, A.Polzonetti, "Best practice in advanced enterprise knowledge engineering". Advances in Intelligent Systems and Computing, 2018. 721, c. 211-223.

[9] A.Lewandowska-Ciszek, "Theory of constraints as a stimulus towards warehouse transformation process on the example of the distribution center", Management and Production Engineering Review, 2018, 9(4), c. 96-105.

[10] V.V. Tsyganov, S.A. Savushkin, "Optimization of the service catalog of a large-scale corporation", 10th International Conference Management of Large-Scale System Development, MLSD 2017, 8109699.

[11] L.V. Massel, T.N. Vorozhtsova "Ontological Engineering of Knowledge Space for Situational Management in Russian EnergySector", 3rd Russian-Pacific Conference on Computer Technology and Applications (RPC), 2018.

[12] G. Elahi, E. Yu, N. Zannone, A Modeling "Ontology for Integrating Vulnerabilities into Security Requirements conceptual Foundations", in Proceeding of International Symposium "Rule Interchange and Applications" (2009) pp. 99-114. [online], available: https://link.springer.com/content/pdf/10.1007\%2F978-3-64204840-1.pdf.

[13] K. Tomingas, P.Järv, T. Tammet, "Computing data lineage and business semantics for data warehouse". Communications in Computer and Information Science, 2019, 914, c. 101-124.

[14] A. Afanasyev, N. Voit, "Intelligent agent system to analysis manufacturing process models", / Advances in Intelligent Systems and Computing. 2016. T. 451. C. 395-403. 